* Mestrado Profissionalizante em Controladoria Empresarial / Ciências Contábeis pela Universidade Presbiteriana Mackenzie, Brasil(2010). Consultor Tributário da SEFAZ-SP do Secretaria da Fazenda de São Paulo, Brasil. E-mail: betobiava@uol.com.br

\section{Alguns questionamentos sobre a Responsabilidade Tributária dos Sócios e Administradores (artigo 135 do Código Tributário Nacional - CTN) e o redirecionamento da Execução Fiscal}

\author{
Some Questions about The Tax Liability of \\ Partners and Managers (Article 135 of the \\ National Tax COde - CTN) AND THE \\ REDIRECTION OF TAX ForECLOSURE
}

\author{
Roberto Biava Júnior *
}

Resumo: O presente artigo analisou importantes questionamentos relativos à responsabilidade tributária (prevista no artigo 135 do Código Tributário Nacional - CTN) em face do frequente redirecionamento das execuções fiscais aos sócios e administradores das empresas, analisando este dispositivo tanto do ponto de vista de sua natureza jurídica (uma análise da doutrina), como também do ponto de vista da jurisprudência dominante nos tribunais superiores (no Supremo Tribunal Federal - STF e Superior Tribunal de Justiça - STJ), procurando responder alguns questionamentos polêmicos como: a natureza jurídica da responsabilidade tributária (artigo 135); possibilidade de redirecionamento da execução físcal para as pessoas dos sócios e administradores; a análise de alguns casos específicos como: o simples inadimplemento, a dissolução irregular da sociedade e a falência da empresa.

Palavras-Chave: responsabilidade tributária; sócios e administradores; execução fiscal.

Abstract: This paper analyzed important questions concerning the tax liability (under article 135 of the National Tax Code CTN) in face of frequent redirection of tax foreclosure to partners and managers of companies, analyzing this legal provision in terms of legal nature (a review of the legal literature), as well as from the perspective of the dominant jurisprudence in the higher courts (Supreme Court - STF e Superior Court of Justice - STJ), trying to answer some controversial questions such as: the legal nature of the tax liability (article 135); possibility of redirecting tax enforcement suits to individuals who are private company partners; analysis of some specific cases such as the simple default, the irregular dissolution of the company and the company's bankruptcy.

Keywords: tax liability; partners and managers; tax foreclosure. 


\section{INTRODUÇÃO (DÚVIDAS PROPOSTAS A RESPEITO DO TEMA)}

A elaboração do presente artigo visa sanar algumas dúvidas e questionamentos importantes não apenas do ponto de vista doutrinário, mas também do ponto de vista eminentemente prático e jurisprudencial, uma vez que são dúvidas pertinentes à relação jurídico-tributária entre fisco e contribuinte.

Chamo-nos a atenção especialmente a temática da natureza jurídica da responsabilidade tributária dos sócios e administradores, constante do artigo 135 do Código Tributário Nacional (CTN), e do frequente redirecionamento das execuções fiscais a estes referidos sócios e administradores, surgindo diversas dúvidas teóricas e práticas a respeito do tema, a qual pretenderemos enfrentar:

a) Qual seria a natureza jurídica da responsabilidade do artigo 135 do $\mathrm{CTN}^{1}$ ? Seria uma responsabilidade tributária solidária, subsidiária, por substituição, ou até mesmo uma responsabilidade oriunda de norma nãotributária? Quais as implicações práticas?

b) É possível o redirecionamento da Execução Fiscal nas hipóteses do artigo 135 do CTN? E se o auto de infração originalmente não foi lavrado contra o administrador ou sócio? E se o administrador ou sócio não constam na Certidão de Dívida Ativa-CDA?

c) O simples inadimplemento justifica a responsabilidade dos sócios ou administradores? E os casos de dissolução irregular da sociedade e de falência implicam na responsabilidade dos sócios e administradores?

\section{QUEM PODE PRATICAR AS CONDUTAS DO ARTIGO 135 DO CTN}

Para conhecermos os possíveis sujeitos passivos do inciso I do art. 135, devemos também nos remeter às pessoas listadas no art. 134 do $\mathrm{CTN}^{2}$. Devese atentar para a correta identificação dos agentes realizadores das condutas

\footnotetext{
${ }^{1}$ Artigo 135 do CTN: "Art. 135. São pessoalmente responsáveis pelos créditos correspondentes a obrigações tributárias resultantes de atos praticados com excesso de poderes ou infração de lei, contrato social ou estatutos: I - as pessoas referidas no artigo anterior; II - os mandatários. prepostos e empregados; $\underline{\text { III - os diretores, gerentes ou representantes de pessoas jurídicas de direito }}$ privado."

2 "Art. 134. Nos casos de impossibilidade de exigência do cumprimento da obrigação principal pelo contribuinte, respondem solidariamente com este nos atos em que intervierem ou pelas omissões de que forem responsáveis:

I - os pais, pelos tributos devidos por seus filhos menores;
} 
previstas no artigo 135, com o intuito de promover a responsabilização ali enunciada nos limites estabelecidos na norma.

Já quanto aos incisos II e III, ambos do artigo 135, enquadram-se como possíveis autores daqueles atos, os administradores da sociedade, os quais podem ser sócios, acionistas, mandatários, prepostos, empregados, diretores, gerentes ou representantes.

Uma dúvida que aparece na jurisprudência administrativa e judicial se refere à questão de quem pode ser considerado "preposto" no sentido lato sensu (aí enquadrando os diretores, gerentes, representantes, e empregados com poderes da administração).

Por exemplo, no caso dos gerentes (sejam ou não também estes sócios), devemos ter em mente que sua responsabilidade somente se configura quando, no exercício da atividade de administração da pessoa jurídica, restar demonstrado que este agiu com abuso de poder, infração à lei, contrato social ou estatutos, a teor do disposto no artigo 135 do CTN. ${ }^{3}$

Outro exemplo, que podemos citar é a situação do "contador”, que pode ser empregado ou administrador da empresa (em multinacionais, por exemplo, o "contador" às vezes assume função gerencial importante, os chamados "controllers"), mas também pode ser um prestador de serviço terceirizado. No primeiro caso - como administrador -, certamente responderá se praticar os atos previstos no artigo 135, e no segundo caso - contador terceirizado -, terá que haver provas mais robustas de que o mesmo tinha autonomia de decisão sobre os atos que lhe eram confiados.

Um critério, certamente válido para os casos mais duvidosos, é o de que não devem figurar neste rol pessoas sem poderes de decisão sobre a realização dos fatos jurídicos que possam resultar em obrigações tributárias, bem como aqueles que, mesmo possuindo tais poderes, não tiveram participação no ilícito ou no ato realizado com excesso de poderes ou infração ao contrato social e estatuto.

II - os tutores e curadores, pelos tributos devidos por seus tutelados ou curatelados;

III - os administradores de bens de terceiros, pelos tributos devidos por estes;

IV - o inventariante, pelos tributos devidos pelo espólio;

V - o síndico e o comissário, pelos tributos devidos pela massa falida ou pelo concordatário;

VI - os tabeliães, escrivães e demais serventuários de ofício, pelos tributos devidos sobre os atos praticados por eles, ou perante eles, em razão do seu ofício;

VII - os sócios, no caso de liquidação de sociedade de pessoas.

Parágrafo único. O disposto neste artigo só se aplica, em matéria de penalidades, às de caráter moratório."

${ }^{3}$ REsp 197278 -AL - RECURSO ESPECIAL 1998/0089605-8; Relator(a) Ministro FRANCIULLI NETTO; Órgão Julgador: T2 - SEGUNDA TURMA; Data do Julgamento: 26/02/2002; Data da Publicação/Fonte: DJ 24/06/2002. 


\section{CARACTERIZAÇÃO DAS CONDUTAS QUE ENSEJAM A RESPONSABILIDADE DO ARTIGO 135 DO CTN}

As condutas realizadas pelas pessoas acima indicadas e que levam à responsabilização pessoal, segundo o artigo 135 do CTN, são aquelas (A) executadas com excesso de poderes, $(\mathrm{B})$ infração à lei ou ao $(\mathrm{C})$ contrato social ou estatutos:

A) Excesso de poderes: é dever dos administradores em zelar pelos interesses da sociedade, buscando atuar de acordo com sua finalidade, explicitada em seu objetivo social, tal qual definido no estatuto ou contrato social. Em última instância, são estes instrumentos contratuais que identificam os limites da atuação dos representantes da empresa.

Por conta disso, ao praticar atos de gestão em conformidade com a previsão contratual, o administrador desenvolve regularmente sua função, criando obrigações ou gerando direitos de forma legítima para a pessoa jurídica representada. Entretanto, caso a atuação do administrador se dê além do mandato a ele conferido, ou seja, extrapolando os poderes concedidos pela sociedade, encontra-se caracterizado o excesso de poder.

Detalhe interessante ressaltado por Maria Rita Ferragut (2009, p. 128) é que o fato praticado pelo administrador deve tipificar-se como "além do autorizado", não ferindo expressamente nenhuma disposição expressa contida no contrato social ou na própria legislação. Isto porque, nesta última hipótese, estar-se-ia diante de infração do contrato social ou da lei, e não meramente de atuação com excesso de poderes.

Da mesma forma, é evidente que nem todos os atos possíveis de realização pelo administrador estão expressamente contemplados no contrato social. De fato, o administrador encontra-se autorizado a efetuar todos os atos pertinentes à gestão da sociedade, independentemente de menção expressa a eles, conforme o disposto no caput do artigo 1.015 do Código Civil $^{4}$.

B) Infração de Lei: a princípio, qualquer conduta contrária ao ordenamento jurídico pode ser considerada como infração à lei, o que geraria, em tese, a responsabilização direta dos administradores. No entanto, se tal regra fosse seguida à risca, os representantes da sociedade seriam sempre

\footnotetext{
4 "Art. 1.015. No silêncio do contrato, os administradores podem praticar todos os atos pertinentes à gestão da sociedade; não constituindo objeto social, a oneração ou a venda de bens imóveis depende do que a maioria dos sócios decidir."
}

REVISTA DO DIREITO PÚBLICO, Londrina, v.8, n.1, p.101-114, jan./abr.2013 
pessoalmente responsáveis, por qualquer infração legal cometida, o que implicaria o fim da personalidade jurídica da empresa.

Resta-nos indicar, portanto, quais disposições legais levariam à efetiva responsabilização dos administradores quando infringidas por eles no exercício da gestão da sociedade. Parte da doutrina (Maria Rita Ferragut após interpretar Renato Lopes Becho) indica fazer parte deste conjunto "toda proposição prescritiva vinculada ao exercício da administração, cujo desrespeito implique a ocorrência dos fatos jurídicos tributários" (FERRAGUT, 2009, p. 129, apud BECHO, p.181).

Em outras palavras, estariam fora do escopo da responsabilização prevista no artigo 135 do CTN, aquelas infrações à lei que não resultem numa obrigação tributária, tais como as de natureza ambiental ou as de trânsito, por exemplo.

C. Infração do Contrato Social ou do Estatuto: caracteriza-se como infração do contrato social ou do estatuto o desrespeito a dispositivo expresso previsto nestes diplomas, por parte do administrador. Novamente, a ação contrária ao texto destes instrumentos societários, realizada dolosamente (ou também culposamente, para aqueles que entendem que o artigo 135 do CTN pode abarcar atos culposos), deve levar ao nascimento de uma obrigação tributária, para que a responsabilização do administrador ocorra com base no artigo 135 do CTN.

\section{DÚVIDAS ENFRENTADAS PELA JURISPRUDÊNCIA: As situações de: a) Falta de Pagamento do Tributo; b) Dissolução Irregular da Sociedade, c) Falência e Ausência de Pedido de Autofalência) ensejam a responsabilidade do artigo 135 do CTN? Podem se caracterizar como "infração à lei"?}

a) Falta de Pagamento do Tributo: A simples falta de pagamento do tributo não é suficiente para se caracterizar como infração de lei, na acepção dada ao caput do artigo 135 do CTN. Posição majoritária da doutrina entende dessa forma, pelo motivo de que a ilicitude referida no citado artigo, deve ser anterior à ocorrência do fato jurídico tributário. Em outros termos, o administrador deve optar por praticar uma determinada ação, ilícita, que desembocará no nascimento da obrigação tributária posteriormente inadimplida.

Embora nas decisões de primeiro grau existam decisões em sentido contrário, o STJ tem jurisprudência firmada entendendo não ser suficiente a falta de pagamento do tributo para a responsabilização prevista no artigo 135 do CTN. Abaixo, seguem alguns exemplos desse posicionamento: 
"A jurisprudência deste Superior Tribunal é assente no sentido de que a imputação da responsabilidade prevista no art. 135, III, do CTN não está vinculada apenas ao inadimplemento da obrigação tributária, mas à comprovação das demais condutas nele descritas: prática de atos com excesso de poderes ou infrações de lei, contrato social ou estatutos. Assim, não há por que falar em responsabilidade objetiva." ${ }^{5}$

“A responsabilidade tributária prevista no art. 135, III, do CTN, imposta ao sócio-gerente, ao administrador ou ao diretor de empresa comercial só se caracteriza quando há dissolução irregular da sociedade ou se comprova a prática de atos de abuso de gestão ou de violação da lei ou do contrato. (...) Os sócios da sociedade de responsabilidade limitada por cotas não respondem objetivamente pela dívida fiscal apurada em período contemporâneo a sua gestão, pelo simples fato de a sociedade não recolher a contento o tributo devido, visto que, o não-cumprimento da obrigação principal, sem dolo ou fraude, apenas representa mora da sociedade contribuinte e não 'infração legal' deflagradora da responsabilidade pessoal e direta do sócio da sociedade." 6

“A Primeira Seção, no julgamento do REsp 1.101.728/SP, Rel. Ministro Teori Albino Zavascki, submetido ao rito dos recursos repetitivos, consolidou entendimento segundo o qual "a simples falta de pagamento do tributo não configura, por si só, nem em tese, circunstância que acarreta a responsabilidade subsidiária do sócio, prevista no art. 135 do CTN. É indispensável, para tanto, que tenha agido com excesso de poderes ou infração à lei, ao contrato social ou ao estatuto da empresa." 7

b) Dissolução Irregular da Sociedade: $\mathrm{O}$ encerramento das atividades de uma pessoa jurídica, de modo irregular, pode implicar a responsabilização pessoal de seus sócios. Assim vêm entendendo os tribunais, conforme verificamos no acórdão do Recurso Especial n ${ }^{\circ}$ 28.142-1-SP, proferido pelo STJ em 08.09.98. Na referida decisão, o STJ entendeu que, em vista do seu desaparecimento, a empresa extinguiu-se irregularmente, recaindo a responsabilidade tributária por substituição no sócio-gerente, nos termos do artigo 135 do CTN.

\footnotetext{
${ }^{5}$ REsp 573.849-PR, Rel. Min. João Otávio de Noronha, julgado em 26/9/2006.

${ }^{6}$ RE 121.021-PR, Rel. Min. Nancy Andrighi, DJU de 11.09.00.

${ }^{7}$ AgRg no REsp 1265515 / AP; AGRAVO REGIMENTAL NO RECURSO ESPECIAL 2011/01635308; Relator(a) Ministro HUMBERTO MARTINS; Órgão Julgador: T2 - SEGUNDA TURMA; Data do Julgamento: 14/02/2012; Data da Publicação/Fonte: DJe 23/02/2012.
} 
c) Falência e Ausência de Pedido de Autofalência: Uma discussão doutrinária e jurisprudencial importante baseia-se na discussão se a falência pode ser caracterizada como "infração à lei", levando os sócios a responderem nos termos do artigo 135 do CTN. Freqüentemente, a Procuradoria da Fazenda Nacional pede no Judiciário o redirecionamento da execução que era movida contra a pessoa jurídica para as pessoas físicas dos sócios, apresentando a falência como único fundamento.

De qualquer forma, o Judiciário por meio do STJ tem mantido uma linha decisória coerente, no sentido de que deverão ser apresentadas as provas dos atos mencionados no artigo 135 do CTN. Haja vista a jurisprudência vigente entendeu o STJ que:

A falência da empresa não leva os sócios à condição de co-obrigados na responsabilidade tributária. Necessário apurar se houve infração à lei, contrato social, estatuto, ou se houve dissolução irregular da sociedade, o que, conforme o art. 135 do CTN, poderia ensejar a responsabilidade pessoal do dirigente, sendo necessário comprovar, ainda, que este agiu dolosamente, com fraude ou excesso de poderes. ${ }^{8}$

Com relação à ausência de "pedido de autofalência" por parte dos sóciosadministradores da sociedade, entende o STJ que:

[...] não merece prosperar a alegação de violação de lei ante a ausência do requerimento de autofalência. Também esse Superior Tribunal já se posicionou no sentido de que a mera ausência de requerimento não é suficiente para ensejar o redirecionamento. ${ }^{9}$

\section{A NATUREZA JURÍdICA DA RESPONSABILIDADE DO ARTIGO 135 DO CTN NA DOUTRINA}

A primeira grande pergunta que surge da análise sobre o respectivo artigo diz respeito à qual tipo de responsabilidade quis o legislador criar:

a) Responsabilidade Tributária por Substituição: na qual a sujeição passiva da relação jurídica tributária é composta exclusivamente pelas pessoas

\footnotetext{
${ }^{8}$ REsp 718.541-RS, Rel. Min. Eliana Calmon, julgado em 19/4/2005, com precedentes citados: REsp 652.858-PR, DJ 16/11/2004, e REsp 212.033-SC, DJ 16/11/2004.

${ }^{9}$ REsp 573.849-PR, Rel. Min. João Otávio de Noronha, julgado em 26/9/2006, com precedentes citados: AgRg no REsp 586.020-MG, DJ 31/5/2004; AgRg no REsp 570.096-SC, DJ 10/5/2000; REsp 757.918-RS, DJ 20/2/2006, e REsp 700.770-RS, DJ 16/5/2005.
}

REVISTA DO DIREITO PÚBLICO, Londrina, v.8, n.1, p.101-114, jan./abr.2013 
mencionadas no artigo 135, como se os contribuintes ditos “originários” nem fizessem parte da relação jurídica, ou;

b) Responsabilidade Tributária Solidária: na qual a sujeição passiva é tanto do contribuinte originário, como das pessoas mencionadas no artigo 135, com os efeitos regulados pelos artigos 124 e 125 do CTN que tratam da solidariedade, ou;

c) Responsabilidade Tributária Subsidiária: na qual respondem inicialmente os contribuintes originários e, subsidiariamente, as pessoas arroladas no artigo 135 ou ainda;

d) Responsabilidade Civil (norma não-tributária): na qual a referida norma não teria natureza tributária, e sim natureza civil punitiva, procurando atribuir a quem cometeu os atos ilícitos tipificados na norma, a responsabilidade pelo seu cumprimento, tendo, também efeito obrigacional entre as partes (responsável que cometeu o ilícito e contribuinte).

A doutrina a respeito não traz uma posição unânime, havendo divergência de entendimento sobre a natureza e os efeitos de tal responsabilidade tributária.

Maria Rita Ferragut (2009, p.118-119) entende, por exemplo, que, nas hipóteses do artigo 135, o terceiro tornaria-se responsável individualmente pelas conseqüências advindas de seu ato ilícito ou com excesso de poderes, bem como quando partícipe ou mandante. A pessoa jurídica, realizadora do fato tributário, estaria eximida de qualquer obrigação, embora seja quem realizou o evento que fundamenta a relação jurídico-tributária. Dessa forma, defende que esta responsabilidade seria "pessoal", no sentido de "exclusiva" e não subsidiária ou solidária.

Por sua vez, Luciano Amaro afirma ser a responsabilidade do artigo 135, um tipo de responsabilidade por substituição. Isto porque, para tal autor, esse dispositivo excluiria do pólo passivo da obrigação a figura do contribuinte, colocando no seu lugar o executor dos atos previstos no artigo 135. Por fim, o mesmo aduz que "[...] a responsabilidade pessoal deve ter aí o sentido (que já se adivinhava no artigo 131) de que ela não é compartilhada com o devedor original ou natural". Conclui ainda que "[...] não se trata, portanto, de responsabilidade subsidiária de terceiro, nem de responsabilidade solidária. Somente o terceiro responde, pessoalmente" (AMARO, 2005, p.327).

Também Renato Lopes Becho aponta simpatia para esta linha argumentativa entendendo em sua interpretação que "a expressão 
'respondem pessoalmente', contida no artigo 135 do CTN, afasta a responsabilização do contribuinte, sempre que esse dispositivo legal for aplicado [...] que, nos termos como estipulado pelo legislador, não pode haver solidariedade entre contribuintes e responsáveis quando for aplicado o indigitado texto legal”. (BECHO, 2010, p.117).

Na mesma linha de raciocínio, temos os apontamentos de Hamilton Dias de Souza (SOUZA, 2007, p.56-58), sendo que para o referido jurista, a regra do artigo 135 retiraria a solidariedade prevista no artigo 134, havendo a transferência integral da responsabilidade para os terceiros, exonerando o contribuinte original. Assim, entende referido autor que a responsabilidade, nesta hipótese, passa a ser pessoal, plena e exclusiva desses terceiros, mas pondera, que neste caso os atos do sócios e o administradores devem ser necessariamente dolosos e devem ser estranhos ou alheios aos interesses da sociedade (da empresa).

Também neste sentido, o Professor Ives Gandra da Silva Martins analisando "se a responsabilidade das pessoas mencionadas no referido artigo, quando agindo em nome de pessoas jurídicas ,excluiria a responsabilidade destas" entende que sim ("a responsabilidade das pessoas físicas seria excludente da responsabilidade das pessoas jurídicas"), mas pontua a opinião divergente de Henry Tilbery, que "discordou da tese acima, entendendo que a não-menção à solidariedade não a excluiria [...]" (MARTINS, 2002, p.270-271).

Já na lição de Aliomar Baleeiro (1999, p.756), o artigo 135 transferiria o débito originalmente nascido em nome do contribuinte, exclusivamente para o responsável, que o substituiria. Indica que a lei infringida seria a lei comercial ou a civil, não a tributária, de forma que o terceiro agiria contra os interesses da sociedade. Por conta desse fato, estaria justificada a exclusão do contribuinte do pólo passivo.

A linha de raciocínio apresentada pelo Professor Paulo de Barros Carvalho, vê a responsabilização do artigo 135 como uma sanção administrativa, ou seja, uma obrigação não-tributária. Segundo nos informa "nosso entendimento é no sentido de que as relações jurídicas integradas por sujeitos passivos alheios ao fato tributado apresentam a natureza de sanções administrativas" (CARVALHO, 2010, p.388).

Diferentemente, Hugo de Brito Machado (2005, p.167) opta pela solidariedade tributária. Defende, por exemplo, que o artigo 135, I quando comparado ao artigo 134 do CTN, leva ao entendimento de que tais pessoas 
"deixam de responder apenas na impossibilidade de exigência do cumprimento da obrigação principal pelo contribuinte, e passam à posição de responsáveis solidários”.

No mesmo sentido segue o raciocínio do Professor Vittorio Cassone (2006, p.289), para quem o referido dispositivo legal realmente prevê, de forma indireta, a exclusão da responsabilidade tributária da pessoa jurídica, atribuindoa à pessoa física que cometeu o excesso não autorizado. No entanto, entende o autor não haver caso de responsabilidade pessoal exclusiva, "mas, em verdade, opera-se a solidariedade".

\section{O ENTENDIMENTO PREDOMINANTE DA JURISPRU- DÊNCIA (STJ/STF): A RESPONSABILIDADE SUBSIDIÁRIA E SOLIDÁRIA}

Ao analisarmos a jurisprudência, vemos que freqüentemente os tribunais são provocados pelas diversas procuradorias do pólo ativo (União, Estados ou Município) para que seja feito o redirecionamento de determinada execução fiscal, que originalmente era movida contra o sujeito passivo apontado na CDA - Certidão da Dívida Ativa, para um dos responsáveis apontados no artigo 135 do CTN, que na maioria das vezes são os próprios sócios ou administradores da autuada.

Até mesmo a jurisprudência vigente do $\mathrm{STF}^{10}$ aponta para a possibilidade da execução fiscal incidir não somente contra o devedor constante da CDA, mas também contra o responsável tributário, cuja responsabilidade não tinha sido apontada no processo administrativo, e só foi apurada judicialmente em fase de execução.

Ou seja, poder-se-ia "em tese" nem sequer ser apurada a responsabilidade do artigo 135 nas vias administrativas, e desde que a procuradoria do ente competente consiga juntar elementos na via judicial para comprovação dos atos e condutas do artigo 135 por parte do responsável (na maioria das vezes, sócios e administradores), a execução poderia ser redirecionada para os responsáveis, ainda que os mesmos não estejam inscritos em dívida ativa pelo título executivo da CDA.

\footnotetext{
10 "Execução Fiscal. Bens particulares de sócio de sociedade por quotas de responsabilidade limitada. Não se exige a inscrição do nome do sócio-gerente, ou responsável para que contra ele se exerça a ação fiscal. Mas só se admite a responsabilidade do sócio-gerente ou responsável; principalmente se agiu com excesso de poderes ou infração de lei, contrato social ou estatutos (artigo 135, III do CTN). Orientação da Corte. Recurso Extraordinário não conhecido." (RE 107322, DJ 14-111985, p. 20571).
}

REVISTA DO DIREITO PÚBLICO, Londrina, v.8, n.1, p.101-114, jan./abr.2013 
O próprio $\mathrm{STF}^{11}$, em julgados mais antigos, já se posicionou expressamente pela natureza jurídica de "responsabilidade por substituição" (na verdade, no sentido de "responsabilidade subsidiária") para o artigo 135 do CTN. Informa claramente que por força da aplicação do artigo 568, V, do Código de Processo Civil, seria possível a execução fiscal contra os responsáveis tributários (aqui entendidos expressamente como responsáveis por substituição), que podem ser citados e ter bens penhorados desde que presentes as circunstâncias de fato do artigo 135 do CTN.

Por outro lado, o $\mathrm{STJ}^{12}$ tem diversos posicionamentos no sentido de que, quando já lavrada a autuação também no nome do sócio, e, portanto, "constando o nome do sócio-gerente como co-responsável tributário na CDA cabe a ele o ônus de provar a ausência dos requisitos do art. 135 do CTN, independentemente se a ação executiva foi proposta contra a pessoa jurídica e contra o sócio ou somente contra a empresa, tendo em vista que a CDA goza de presunção relativa de liquidez e certeza, nos termos do art. 204 do CTN c/c o art. $3^{\circ}$ da Lei n. ${ }^{\circ} 6.830 / 80 " 13$.

Desta forma, da interpretação da jurisprudência vigente no STJ e no STF no que tange à natureza jurídica do artigo 135 do CTN, podemos entender que, para a jurisprudência dos tribunais, tal responsabilidade é na maioria dos casos de caráter subsidiário, o que tornaria possível o redirecionamento da execução fiscal para os casos de comprovação em fase judicial dos atos e condutas do artigo 135 do CTN, por parte dos responsáveis.

11 "Execução fiscal. Legitimação passiva. As pessoas referidas no inciso III do artigo 135 do CTN são sujeitos passivos da obrigação tributaria, na qualidade de responsaveis por substituição, $e$, assim sendo, se lhes aplica o disposto no artigo 568, V, do Código de Processo Civil, não obstante seus nomes não constarem no titulo extrajudicial. Assim podem ser citados - e ter seus bens penhorados - independentemente de processo judicial previo para a verificação da ocorrencia inequivoca das circunstancias de fato aludidas no artigo 135, "caput" do CTN, matéria essa que, no entanto, podera ser discutida, amplamente, em embargos de executado (art. 745 , parte final, do CPC). Recurso extraordinário conhecido e provido" (RE 100920/SP, Rel. Min. Moreira Alves, julgado em 15/06/84).

12 "A Primeira Seção, no julgamento dos EREsp 702.232/RS, de relatoria do Ministro Castro Meira, assentou entendimento no sentido de que: (a) se a execução fiscal foi promovida apenas contra a pessoa

jurídica e, posteriormente, foi redirecionada contra sócio-gerente cujo nome não consta da Certidão de Dívida Ativa, cabe ao Fisco comprovar que o sócio agiu com excesso de poderes ou infração de lei, contrato social ou estatuto, nos termos do art. 135 do CTN; (b) se a execução fiscal foi promovida contra a pessoa jurídica e o sócio-gerente, cabe a este o ônus de demonstrar que não incorreu em nenhuma das hipóteses previstas no mencionado art. 135; (c) se a execução foi ajuizada apenas contra a pessoa jurídica, mas o nome do sócio consta da CDA, o ônus da prova também compete ao sócio, em virtude da presunção relativa de liquidez e certeza da referida certidão” (REsp 1080319/SP, Rel. Min. Benedito Gonçalves, julgado em 23/04/2009).

${ }^{13}$ AgRg no AgRg no REsp 881911/SP, Rel. Min. Luiz Fux, julgado em 14/4/2009. 
Já no caso de haver autuação também no nome do sócio (seu nome constar da CDA), para o STJ prevalece a liquidez e certeza do título executivo, onde a responsabilidade do artigo 135 já teria sido "em tese " apurada em âmbito administrativo, e então nestes casos, poder-se-ia interpretar que na prática haveria verdadeira responsabilidade solidária.

\section{CONCLUSÃO: nossa opinião sobre a natureza jurídica da responsabilidade tributária do artigo 135 do CTN e a possibilidade de redirecionamento da Execução Fiscal nestas hipóteses.}

Respondendo às dúvidas originalmente formuladas esta é nossa modesta opinião:

a) Qual a natureza jurídica da responsabilidade do artigo 135 do CTN? Seria uma responsabilidade tributária solidária, subsidiária, por substituição, ou até mesmo uma responsabilidade oriunda de norma não-tributária? Quais as implicações práticas?

R: Entendemos que há realmente "responsabilidade solidária" para aqueles que praticam as condutas dolosas tipificadas no art. 135, quais sejam: atos praticados com (1) excesso de poderes ou (2) infração de lei ou, (3) infração ao contrato social ou estatutos. Ou seja, para aqueles identificados como responsáveis, na forma do artigo 135 , serão aplicáveis os efeitos da solidariedade prevista nos artigos 124 e 125 do CTN.

Desta forma, o contribuinte continuaria fazendo parte do pólo passivo da obrigação tributária nos termos do artigo 121 do CTN. Neste caso, o responsável pelo crédito tributário seria quem praticou quaisquer das condutas tipificadas no artigo 135, o qual poderá/deverá ser incluído de plano no Auto de Infração.

Entendemos que por ser um dispositivo que atribui uma garantia ou privilégio suplementar à Fazenda, o mesmo não obriga a exigência exclusiva do crédito tributário do responsável definido no artigo 135, como querem alguns doutrinadores. Se assim o fosse, teríamos uma norma lesiva ao Fisco, que o colocaria em posição inferior aos particulares.

Caso seja o crédito tributário exigido e pago pelo responsável solidário (administrador ou sócio) nos termos do artigo 135 do CTN, seguirão os efeitos da solidariedade, especialmente o previsto no artigo 125, I do CTN . Ou seja, a exigência direta do crédito tributário por aquele que deu causa ao ilícito constitui um procedimento de verdadeira "economia processual". Isto porque, pelas normas de direito civil e comercial, o contribuinte lesado teria direito de ação de 
regresso contra aquele que dolosamente agiu conforme as condutas previstas no caput do artigo 135 do CTN. É o caso que ocorre quando o administrador da empresa lesa a pessoa jurídica por atos desta natureza, provocando à empresa prejuízos na seara tributária. Neste caso, a cobrança do tributo diretamente do administrador responsável seria uma facilidade processual e uma vantagem para quem foi lesado, no caso o contribuinte originário.

b) É possível o redirecionamento da Execução Fiscal nas hipóteses do artigo 135 do CTN? E se o auto de infração originalmente não foi lavrado contra o administrador ou sócio? E se o administrador ou sócio não constam na Certidão de Dívida Ativa-CDA?

$\mathrm{R}$ : Entendemos correta a jurisprudência vigente do STF que aponta para a possibilidade da execução fiscal incidir não somente contra o devedor constante da CDA, mas também contra o responsável tributário, cuja responsabilidade não tinha sido apontada no processo administrativo, e possa ser apurada judicialmente em fase de execução.

Neste caso, a procuradoria do ente competente deve juntar elementos na via judicial para comprovação dos atos e condutas do artigo 135 por parte do responsável (na maioria das vezes, sócios e administradores), sendo que a execução pode ser redirecionada para os responsáveis, ainda que os mesmos não estivessem mencionados no auto de infração, e não estejam inscritos em dívida ativa pelo título executivo da CDA.

c) O simples inadimplemento justifica a responsabilidade dos sócios ou administradores? E os casos de dissolução irregular da sociedade e de falência implicam na responsabilidade dos sócios e administradores?

$\mathrm{R}$ : Entendemos que a imputação da responsabilidade prevista no art. 135 não configura responsabilidade objetiva, não podendo ser vinculada apenas ao inadimplemento da obrigação tributária, mas à comprovação das demais condutas nele descritas (prática de atos com excesso de poderes ou infrações de lei, contrato social ou estatutos).

De outro modo, o encerramento das atividades de uma pessoa jurídica, de modo irregular, deve implicar a responsabilização pessoal de seus sócios que tenham poderes de gestão e decisão sobre estes atos e tenham incorrido nas condutas do artigo 135 do CTN.

Por outro lado, a falência da empresa por si só, não leva os sócios à condição de co-obrigados na responsabilidade tributária, sendo necessário apurar a responsabilidade pessoal do dirigente nas condutas do artigo 135 do CTN, comprovando se este agiu com fraude ou excesso de poderes. 


\section{REFERÊNCIAS}

AMARO, Luciano. Direito Tributário Brasileiro, $11^{\text {a }}$ Ed., São Paulo, Saraiva, 2005.

BALEEIRO, Aliomar. Direito Tributário Brasileiro, Rio de Janeiro, Forense, 1999.

BECHO, Renato Lopes. Sujeição Passiva e Responsabilidade Tributária, São Paulo, Dialética, 2000.

. A responsabilidade tributária dos sócios tem fundamento legal?, artigo in Revista Dialética de Direito Tributária RDDT, $n^{\circ} 182$, Novembro/2010, p.107-126.

CARVALHO, Paulo de Barros. Curso de Direito Tributário, 22 ${ }^{\mathrm{a}}$ Ed, São Paulo, Saraiva, 2.010.

CASSONE, Vittorio. Direito Tributário, 17ª Ed., São Paulo, Atlas, 2006.

FERRAGUT, Maria Rita. Responsabilidade Tributária e o Código Civil de 2002, São Paulo, Noeses, 2009.

MACHADO, Hugo Brito. Curso de Direito Tributário, 26a Ed., São Paulo, Malheiros, 2005.

MARTINS, Ives Gandra da Silva (coordenador). Comentários ao Código Tributário Nacional - Volume 2. São Paulo, Saraiva, 2002.

SOUZA, Hamilton Dias de; FUNARO, Hugo. A desconsideração da personalidade jurídica e a responsabilidade tributária dos sócios e administradores, artigo in Revista Dialética de Direito Tributária RDDT, $n^{\circ}$ 137, Fevereiro/2007, p.38-65.

Recebido em: 07/08/2012 Aprovado para publicação em: 08/04/2013

Como citar: BIAVA JÚNIOR, Roberto. Alguns Questionamentos sobre a Responsabilidade Tributária dos Sócios e Administradores (artigo 135 do Código Tributário Nacional - CTN) e o Redirecionamento da Execução Fiscal. Revista do Direito Público,Londrina, v.8,n.1, p.101-114, jan./abr.2013.DOI: 10.5433/1980-511X.2013v8n1p101. 